\title{
Evidence of mast-cell activation in a subset of patients with eosinophilic chronic obstructive pulmonary disease
}

\author{
R.E. Louis*, D. Cataldo*, M.G. Buckley\#, J. Sele*, M. Henket*, L.C. Lau\#, P. Bartsch*, A.F. Walls", \\ R. Djukanovic ${ }^{\#}$
}

Evidence of mast-cell activation in a subset of patients with eosinophilic chronic obstructive pulmonary disease. R.E. Louis, D. Cataldo, M.G. Buckley, J. Sele, M. Henket, L.C. Lau, P. Bartsch, A.F. Walls, R. Djukanovic. (C)ERS Journals Ltd 2002. ABSTRACT: Although asthma has been viewed mainly as an eosinophilic disease, and chronic obstructive pulmonary disease (COPD) as a neutrophilic disease, recent studies have shown increased neutrophil counts in severe asthma and sputum eosinophilia in some COPD patients.

In an attempt to further characterise these two syndromes according to pathology, the current authors have conducted a study of induced sputum in 15 subjects with COPD, 17 asthmatics, and 17 nonatopic healthy individuals. Sputum was analysed for cytology and levels of eosinophil cationic protein (ECP), albumin, tryptase and soluble intercellular adhesion molecule-1.

The COPD subjects differed from the asthmatics as they had higher sputum neutrophil and lower columnar epithelial cell counts, but there were no differences in any soluble marker studied. When compared to control subjects, both the asthmatic and COPD subjects had raised eosinophil counts and ECP levels. In a subset of COPD subjects with sputum eosinophilia ( $>3 \%$ of total cells), significantly increased levels of tryptase were detected.

In conclusion, although chronic obstructive pulmonary disease is a more neutrophilic disease than asthma, the two diseases are difficult to distinguish on the basis of sputum levels of the soluble markers traditionally associated with asthma. However, a subset of patients with chronic obstructive pulmonary disease with airway eosinophilia and mastcell activation might represent a distinct pathological phenotype.

Eur Respir J 2002; 20: 325-331.

\author{
*Dept of Pneumology, Centre Hospital- \\ ier Universitaire (CHU) Sart-Timan, \\ University of Liège, Liège, Belgium. \\ ${ }^{\#}$ Respiratory Cell and Molecular Bio- \\ logy Research Division, University of \\ Southampton, Southampton, UK. \\ Correspondence: R. Louis \\ CHU Sart-Tilman \\ Dept of Pneumology \\ University of Liège \\ Avenue de l'hôpital \\ 4000 Liège \\ Belgium \\ Fax: 3243668846 \\ E-mail: R.Louis@chu.ulg.ac.be \\ Keywords: Asthma \\ chronic obstructive pulmonary disease \\ inflammatory cells \\ mediators \\ sputum
}

Received: October 162001

Accepted after revision: March 12002
Asthma and chronic obstructive pulmonary disease (COPD) are common pulmonary inflammatory diseases. Although both are characterised physiologically by airflow limitation, this tends to be irreversible in COPD while in asthma it is largely reversible, either spontaneously or after bronchodilator administration [1]. The degree of reversibility of forced expiratory volume in one second (FEV1) to $\beta_{2}$-agonists allowed when labelling a patient as suffering from COPD is set between 12 and $15 \%$, depending on the guidelines recommended by individual respiratory societies [2-4]. Such an arbitrary approach often makes it difficult to make a confident diagnosis of COPD, both for clinical and research purposes. Despite these uncertainties, studies of well-defined asthmatics and COPD patients have identified differences in the cellular mechanisms underlying the two diseases. Lymphocytes of the CD4+ T-cell subset, mast cells, and eosinophils are viewed as the key cells in asthma, whilst evidence suggests that CD8+ T-cells and neutrophils are important in COPD [5]. However, recent studies have shown a significant degree of overlap between asthma and COPD, with raised levels of neutrophils in more severe forms of asthma $[6,7]$ and raised counts and activation of eosinophils in stable COPD [8-10].
These observations clearly question the value of using eosinophils and eosinophil products in the diagnosis of asthma, even though they may still be relatively good markers of disease severity [11-13].

In an attempt to identify markers of inflammation that might better differentiate between asthma and COPD, the current authors previously measured sputum levels of tryptase, a mast cell protease with several inflammatory actions that are associated with allergic diseases [14]. The authors hypothesised that its elevation in sputum is restricted to asthma. In addition, based on the current authors' previous studies in asthma [15], sputum levels of albumin have been compared, reflecting microvascular leakage. This phenomenon is currently thought to be important in the airways instability that characterises asthma [16], but its relevance to COPD, a disease with largely irreversible lung function impairment, is less clear. Finally, sputum levels of soluble intercellular adhesion molecule-1 (sICAM-1) in the sputum fluid phase have been compared. Raised cell surface expression of this adhesion molecule has been convincingly demonstrated in several studies of asthmatic airways $[15,17,18]$, and sICAM-1 has been found to be increased in asthmatic sputum [15]. Whether ICAM-1 is upregulated to the 
same extent in COPD remains uncertain, as the studies published so far have yielded conflicting results $[18,19]$.

\section{Materials and methods}

\section{Subjects}

Seventeen asthmatics, 15 subjects with COPD and 17 healthy control subjects were studied (table 1). The asthmatics had reversible airflow limitation based on an increase in FEV1 $>15 \%$ after inhalation of $400 \mu \mathrm{g}$ salbutamol [1] when FEV1 was $<80 \%$ predicted and/or hyperresponsiveness to methacholine, as judged by the concentration of methacholine causing a $20 \%$ fall in FEV1 $\left(\mathrm{PC}_{20}\right)<16 \mathrm{mg} \cdot \mathrm{mL}^{-1}$, when $\mathrm{FEV} 1$ was $>70 \%$ pred. Two asthmatics were current smokers with 7 and 12 pack-yrs respectively; all the others were lifelong nonsmokers. The COPD subjects were either current $(n=10)$ or ex-heavy smokers $(>20$ pack-yrs) $(\mathrm{n}=5)$ with $\mathrm{FEV} 1 / \mathrm{FVC}<70 \%$ and poor reversibility to $400 \mu \mathrm{g}$ of salbutamol, as shown by an increase in FEV $1<15 \%$ from baseline or $<200 \mathrm{~mL}$ [4]. None of the COPD subjects were atopic, as demonstrated by negative skin-prick tests to common aero-allergens, and none had a clinical history of asthma. The healthy subjects denied chronic respiratory diseases including chronic bronchitis. Five were current smokers with $<10$ pack-yrs; the rest were lifelong nonsmokers. All the subjects had been stable and free of infection at the time of sputum induction for $\geqslant 6$ weeks. The study was approved by the local ethics committee and all subjects gave written informed consent.

Table 1. - Subject characteristics

\begin{tabular}{|c|c|c|c|}
\hline & Healthy subjec & s COPD & Asthma \\
\hline Subjects $\mathrm{n}$ & 17 & 15 & 17 \\
\hline Age yrs & $35 \pm 14$ & $61 \pm 11$ & $39 \pm 12$ \\
\hline Sex M:F & $10: 7$ & $11: 4$ & $10: 7$ \\
\hline Atopy & 1 & 0 & 15 \\
\hline Current smoking & 5 & 10 & 2 \\
\hline FEV1 $\%$ pred & $104 \pm 6$ & $54 \pm 21$ & $83 \pm 12$ \\
\hline FEV1/FVC \% & $84 \pm 9$ & $54 \pm 14$ & $74 \pm 11$ \\
\hline PEFR $\mathrm{L} \cdot \mathrm{min}^{-1}$ & $508 \pm 105$ & $305 \pm 146$ & $467 \pm 111$ \\
\hline $\begin{array}{l}\text { FEV1 reversibility } \\
\% \text { baseline }\end{array}$ & ND & $9 \pm 5^{\#}$ & $19 \pm 7^{\top}$ \\
\hline $\mathrm{PC}_{20} \mathrm{M} \mathrm{mg} \cdot \mathrm{mL}^{-1}$ & $>16$ & ND & $0.36(0.03-13.2)$ \\
\hline$D \mathrm{~L}, \mathrm{CO} / V \mathrm{~A} \%$ pred & ND & $62 \pm 22$ & $91 \pm 12$ \\
\hline Inhaled steroids & 0 & 3 & 3 \\
\hline Theophylline & 0 & 2 & 0 \\
\hline
\end{tabular}

Quantitative variables are expressed as mean $\pm \mathrm{SD}$. $\mathrm{PC} 20$ is expressed as geometric mean (range). COPD: chronic obstructive pulmonary disease; M: male; F: female; FEV1: forced expiratory volume in one second; FVC: forced vital capacity; PEFR: peak expiratory flow rate; PC20: provocation concentration causing a $20 \%$ fall in FEV 1 ; D L,CO: carbon monoxide diffusing capacity of the lung; VA: alveolar volume; ND: not determined. \#: four patients with COPD had a reversibility $>15 \%$ but $<200 \mathrm{~mL}$ (range 119 $192 \mathrm{ml}) ;{ }^{\uparrow}:$ six asthmatic patients whose baseline FEV1 was $<80 \%$ had a bronchodilation test.

\section{Sputum induction and analysis}

Subjects were premedicated with $400 \mu \mathrm{g}$ of inhaled salbutamol. Induction was performed using hypertonic saline $(4.5 \%)$ aerosolised by ultrasonic nebuliser (Devilbiss 2000; Devilbiss Healthcare Inc., Somerset, PA, USA) for three periods of $5 \mathrm{~min}$. For safety reasons, isotonic $(0.9 \%)$, instead of hypertonic saline, was used in six subjects with COPD whose baseline peak expiratory flow (PEF) was $<250 \mathrm{~L} \cdot \mathrm{min}^{-1}$. All asthmatic and COPD subjects took their regular medication (table 1) on the morning of the test.

Entire sputum was collected in a plastic container, homogenised with an equal weight of $0.01 \mathrm{M}$ dithiothreitol (DTT; Calbiochem, LaJolla, CA, USA) and processed as previously described [15]. Total and differential cell counts were performed using standard methods. Eosinophil cationic protein (ECP) was measured using the UNICAP system (Pharmacia, Uppsala, Sweden), with a sensitivity of $2 \mathrm{ng} \cdot \mathrm{mL}^{-1}$ and a coefficient of variation $(\mathrm{CV})$ of $3 \%$. Commercial enzyme-linked immunosorbant assay (ELISA) (Biosource, Fleurus, Belgium) was used to measure sICAM-1 according to the manufacturer's instructions and with a sensitivity of $0.35 \mathrm{ng} \cdot \mathrm{mL}^{-1}$ and a CV of $8 \%$. In spiking experiments using DTT-processed sputum, recovery of sICAM-1 was extremely low at a mean of $23 \%$. Studying the effects of DTT on the assay showed that $5 \mathrm{mM}$ DTT shifted the standard curve for sICAM-1 to the right by $>50 \%$. The values in sputum samples were read from a standard curve constructed in a pool of sputum treated with $5 \mathrm{mM}$ DTT, in which the initial assay could not detect any sICAM-1. Albumin was measured by rocket electrophoresis with a sensitivity of $1 \mu \mathrm{g} \cdot \mathrm{mL}^{-1}$ and a CV of $5 \%$ [20]. Validation of the albumin assay in sputum showed $<5 \%$ of effects on the standard curve when this was constructed in the presence of DTT. Recovery of albumin was $>95 \%$ in spiking experiments. Tryptase concentrations were measured using an in-house sandwich ELISA. Samples were applied to microplates coated with rabbit antibodies prepared against human tryptase, and tryptase was detected with biotinylated tryptase-specific monoclonal antibody AA5 [21], Extravidin (R)-peroxidase and $O$-phenylene diamine substrate. Spiking experiments showed good recovery from DTT-processed samples, ranging between $76 \%$ (when samples were spiked with $4 \mathrm{ng} \cdot \mathrm{mL}^{-1}$ tryptase) and $96 \%$ (when spiking with $8 \mathrm{ng} \cdot \mathrm{mL}^{-1}$ tryptase). With human tryptase as the standard, the limit of detection was $0.3 \mathrm{ng} \cdot \mathrm{mL}^{-1}$ and $\mathrm{CV}$ was $<6 \%$.

\section{Statistical analysis}

Comparisons of sputum markers between the three subject groups were performed using a KruskallWallis test followed by a Dunn's test for pairwise analysis when the former test showed significant differences. Comparison between current smokers and nonsmokers in healthy and COPD patients were performed using a Mann-Whitney U-test. Correlation between ECP and eosinophil counts were sought by 
calculating the Spearman coefficient of correlation. p-Values of $<0.05$ were considered statistically significant.

\section{Results}

\section{Sputum cytology}

There was no significant difference between the three subject groups with respect to total and squamous cell counts (table 2). Both the asthmatic and COPD subjects had significantly higher relative and absolute eosinophil counts than healthy subjects $(\mathrm{p}<0.001$ and $\mathrm{p}<0.05$, respectively), with no difference between the patient groups. Subjects with COPD had significantly lower relative macrophage counts than both the healthy subjects $(\mathrm{p}<0.01)$ and the asthmatics $(\mathrm{p}<0.01)$, and higher relative neutrophil counts than the asthmatics $(\mathrm{p}<0.01)$. Furthermore, the asthmatics had higher absolute columnar epithelial cell counts than the subjects with COPD $(p<0.05)$, but these were not higher than in control subjects.

\section{Levels of soluble markers in the sputum fluid phase}

Sputum levels of ECP were similarly increased in both asthma and COPD when compared to those found in healthy subjects $(\mathrm{p}<0.05$ and $\mathrm{p}<0.01$, respectively). Only the asthmatics had significantly raised sputum levels of sICAM-1 $(\mathrm{p}<0.05)$, albumin $(\mathrm{p}<0.05)$ and tryptase $(\mathrm{p}<0.05)$ when compared to control subjects, although these were not significantly different from the levels in COPD subjects (fig. 1).

Comparison of eosinophilic and noneosinophilic chronic obstructive pulmonary disease

Subanalysis of subjects with COPD showed that those with eosinophilia (eosinophil counts $>3 \%$ of total cells, n=7) also had higher tryptase levels when compared to COPD subjects without raised eosinophils $(\mathrm{n}=8)(\mathrm{p}<0.05)$ and the control subjects $(\mathrm{p}<0.05)$ (fig. 2). There were no significant differences between the two groups of COPD subjects in levels of albumin or sICAM-1 ( $>0.05)$. Similarly, the levels of ECP also failed to differ significantly between eosinophilic and noneosinophilic COPD subjects $\left(82 \mathrm{ng} \cdot \mathrm{mL}^{-1}\right.$ (24-2020) versus $\left.52 \mathrm{ng} \cdot \mathrm{mL}^{-1} \quad(25-240), \quad \mathrm{p}>0.05\right)$. Sputum ECP did not correlate with the sputum eosinophil counts in COPD (Spearman rank coefficient $\left.\left(r_{s}\right)=0.22, p>0.05\right)$, whereas it correlated strongly in asthma $\left(\mathrm{r}_{\mathrm{s}}=0.86, \mathrm{p}<0.05\right)$ (fig. 3$)$.

COPD subjects with sputum eosinophil counts $>3 \%$ did not differ significantly from those with low eosinophil counts in terms of age $(62 \pm 10$ versus $60 \pm 12$ yrs) or lung function indices, including FEV1

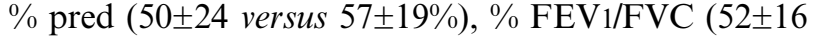
versus $55 \pm 16 \%), \% \mathrm{FEV} 1$ reversibility $(8 \pm 5$ versus $10 \pm 4 \%)$ and carbon monoxide diffusing capacity of the lung $(D \mathrm{~L}, \mathrm{CO}) /$ alveolar volume $(V \mathrm{~A}) \%$ pred $(59 \pm 26$ versus $65 \pm 22 \%)(\mathrm{p}>0.05)$.

\section{Subset analyses according to smoking status}

The influence of current smoking on sputum cells and mediators was tested in healthy controls and COPD subjects but not in asthmatics in whom only two subjects were current smokers.

In healthy controls, current smokers $(n=5)$ had a greater percentage of neutrophils $(65.8 \%(40.2-79))$ and a lower percentage of macrophages $(30.8 \%$ (14.6-52.6)) when compared to their nonsmoking counterparts $(\mathrm{n}=12)(29.3 \%(0.8-65.4), \mathrm{p}<0.05$ and $53.1 \%(32.2-84.8), \quad \mathrm{p}<0.05$, respectively). In the COPD group, the current smokers had lower lymphocyte counts than the exsmokers $(0.2 \%(0-3)$ versus $1.4 \%(1-7.3), \mathrm{p}<0.01)$. No differences between smokers and nonsmokers or exsmokers were found in the groups of healthy controls and COPD subjects with respect to the mediators/proteins (data not shown).

Table 2. - Total and differential sputum cell counts in healthy subjects, chronic obstructive pulmonary disease (COPD) and asthma

\begin{tabular}{lccc}
\hline & Healthy subjects & COPD & Asthma \\
\hline Subjects n & 17 & 15 & 17 \\
Squamous cells \% & $8(0-32)$ & $12(2-50)$ & $14(2-39)$ \\
Total nonsquamous $10^{6} \cdot \mathrm{g}^{-1}$ & $1.09(0.17-4.42)$ & $1.27(0.25-15.6)$ & $1.25(0.17-6.44)$ \\
Macrophages \% & $49.7(14.6-84.8)$ & $21.2(2-54.7)^{* *}$ & $45(10-76)^{\# \#}$ \\
Macrophages $10^{3} \cdot \mathrm{g}^{-1}$ & $516(77-2238)$ & $201(11-4018)$ & $342(33-2237)$ \\
Lymphocytes $\%$ & $1(0-5)$ & $0.6(0-7.3)$ & $1(0-4.8)$ \\
Lymphocytes $10^{3} \cdot \mathrm{g}^{-1}$ & $9(0-150)$ & $7(0-100)$ & $13(0-140)$ \\
Neutrophils $\%$ & $40.2(0-79)$ & $50(10.7-98)$ & $24(4-63.6)^{\# \#}$ \\
Neutrophils $10^{3} \cdot \mathrm{g}^{-1}$ & $235(0-2890)$ & $1.8(100-12823)$ & $374(14-2945)$ \\
Eosinophils $\%$ & $0(0-2.1)$ & $47(0-1435)^{*}$ & $7.8(0-69.4)^{* * *}$ \\
Eosinophils $10^{3} \cdot \mathrm{g}^{-1}$ & $0(0-84)$ & $3.6(0-26)$ & $165(0-4469)^{* *}$ \\
Epithelial cells $\%$ & $5.4(0-52.8)$ & $34(0-2548)$ & $9.2(1.2-29.5)$ \\
Epithelial cells $10^{3} \cdot \mathrm{g}^{-1}$ & $41(0-413)$ & $78(25-670)^{\#}$ \\
\hline
\end{tabular}

Data are presented as median (range). Squamous cells are shown as a percentage of total cells. Other cells are shown as a percentage of total inflammatory (nonsquamous) cells or per weight of sputum. *: $\mathrm{p}<0.05 ;{ }^{* *}: \mathrm{p}<0.01 ;{ }^{* * *}: \mathrm{p}<0.001$ versus healthy subjects; $\#$ : $\mathrm{p}<0.05{ }^{\# \#}: \mathrm{p}<0.01$ versus COPD. 

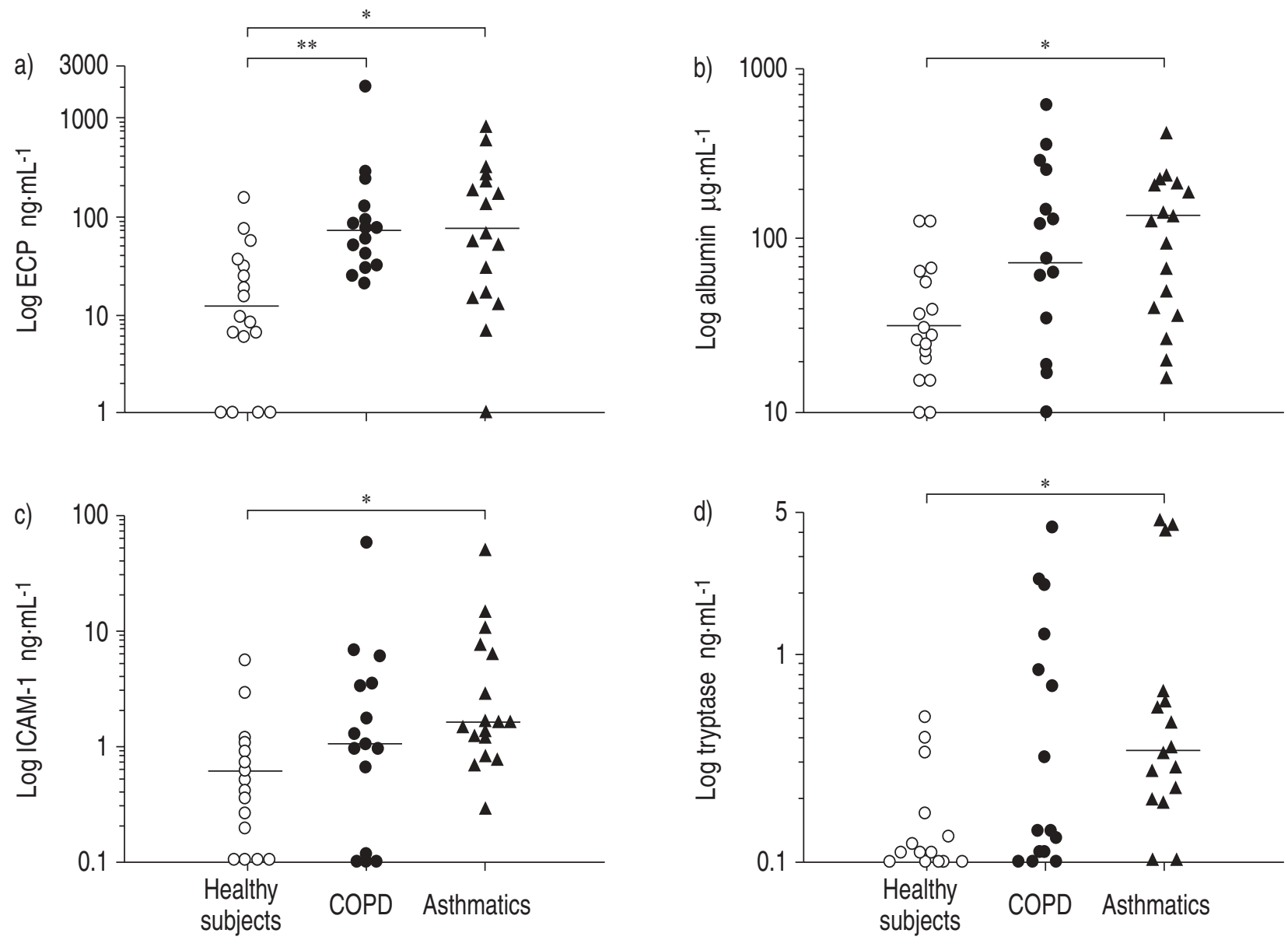

Fig. 1. - Sputum levels of a) eosinophil cationic protein (ECP), b) albumin, c) soluble intercellular adhesion molecule-1 (sICAM-1) and d) tryptase in healthy subjects, chronic obstructive pulmonary disease (COPD) subjects and asthmatics. Bars: median values. *: p<0.05; **: $\mathrm{p}<0.01$.

\section{Discussion}

In this study, previous reports of eosinophilia and eosinophil activation in the airways as shared features

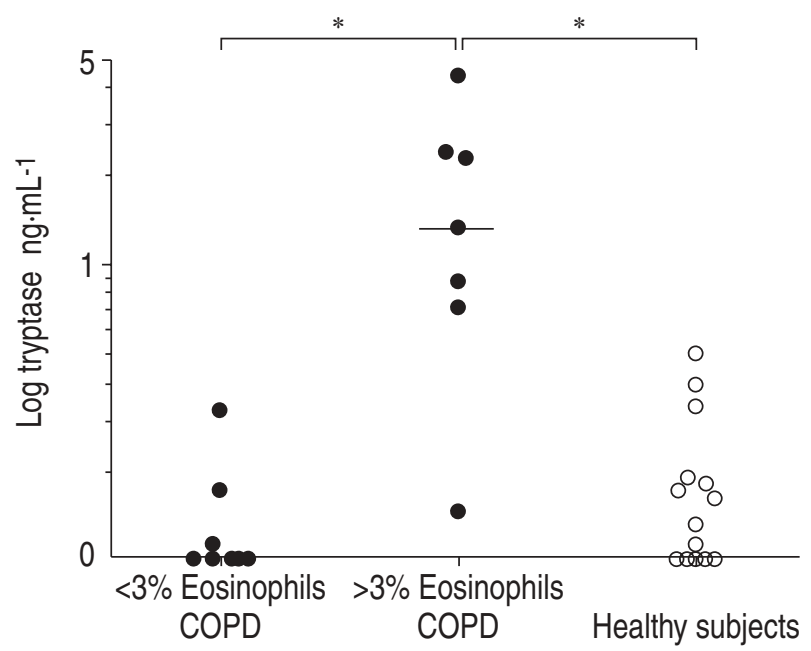

Fig. 2. - Distribution of sputum tryptase levels in healthy subjects and chronic obstructive pulmonary disease (COPD) subjects according to the percentage of sputum eosinophil counts. Bars: median values. *: $\mathrm{p}<0.05$ of asthma and COPD have been confirmed. Contrary to the hypothesis the current authors sought to test, it has been shown that a subset of COPD patients with eosinophil counts above the normal range have raised levels of mast cell tryptase, a feature which has until now been viewed as a hallmark of asthma and other allergic diseases [14]. This study would indicate the existence of a phenotype, which could be called eosinophilic COPD and is characterised by concomitant mast cell and eosinophilic inflammation, the pathophysiological consequences of which remain to be elucidated. The association between mast-cell activation and eosinophilia found in this study in some subjects with COPD is similar to observations of the WENZEL et al. [22] in a subset of severe, corticosteroiddependent asthmatics characterised by persistently raised eosinophil counts in bronchial biopsies.

Whilst many clinicians and researchers recognise that there is significant overlap between what is clinically defined as asthma and COPD, in the absence of clear-cut differences, management guidelines continue to treat these two conditions as distinct entities. There are, however, attempts to treat COPD patients with drugs developed for asthma. Whilst studies with inhaled corticosteroids show some benefit in COPD [23-25], overall the therapeutic effect is markedly smaller than in patients with asthma where striking 

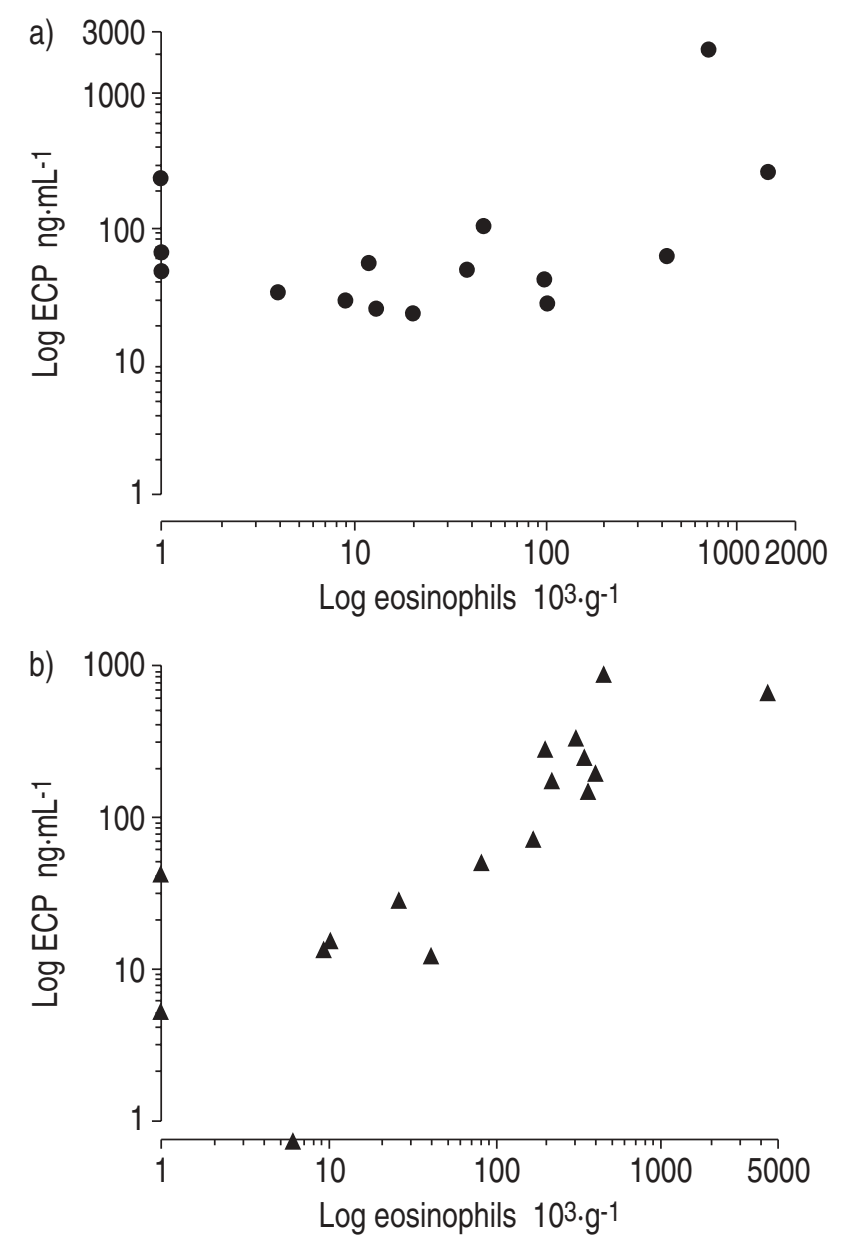

Fig. 3.-Relationship between sputum eosinophils and sputum levels of eosinophil cationic protein (ECP) in a) chronic obstructive pulmonary disease subjects $(\mathrm{r}=0.22, \mathrm{p}>0.05)$ and $\mathrm{b})$ asthmatics $(\mathrm{r}=0.88, \mathrm{p}<0.0001)$.

improvements are typically seen both in clinical and inflammatory indices. A number of studies have recently identified a subgroup of COPD patients with raised eosinophils who respond more favorably to corticosteroids [26-28]. In the light of the finding of raised tryptase in such patients, the current authors propose that responders to steroids have both eosinophil- and mast cell-driven disease regardless of whether they have asthma or COPD, although the magnitude of the response may be different. The observation is entirely in keeping with that made in a study by RUTGERs et al. [29], showing that COPD patients who have sputum eosinophilia display responsiveness to adenosine, an indirect stimulus known to cause airway obstruction in asthmatics by releasing mediators from mast cells.

It is apparent from this study that, despite the noted similarities between COPD and asthma, the sequelae of eosinophilic infiltration and mast-cell activation in terms of physiology in these two conditions are different. As polymorphonuclear leucocytes are an important source of matrix metalloproteases [30], it is conceivable that sputum neutrophilia found in COPD, which is not a feature of mild-to-moderate asthma, may contribute to the development of fixed airway obstruction in COPD.

One potential criticism of this study is the difference in age between the study groups. To the authors' knowledge, age has not been shown to have an influence on sputum cells and mediator levels, although it is plausible that there may be effects on structural elements that are responsible for the natural decline in lung function with age. A recent study [31] has shown that the typical phenotype, consisting of raised eosinophils and collagen deposition, is also seen in older asthmatics. Therefore, in asthmatics, it is likely that age has little effect on the indices that have been studied here. Furthermore, no difference between the cell counts in the control subjects in the current study and 60-yr-old control subjects reported in a recent study [32] were found. Ideally, the subjects would have been matched for the duration of COPD and asthma, respectively, as it is the duration of inflammation that is likely to be more important than biological age. However, the date of the onset of changes in COPD is far too uncertain and the history in asthma sufficiently unreliable that such matching is impossible.

In this study, one important difference seen between asthma and COPD with respect to the eosinophilic inflammation is the lack of relationship between sputum eosinophil counts and ECP in COPD. These patients may sometimes display very high levels of ECP despite low numbers of eosinophils. This suggests that neutrophils are an additional source of ECP [33] or that there is high variability among the patients with respect to the extent of eosinophil degranulation, with some subjects having extensive degranulation despite a modest cell count.

The factors that determine the tissue response in the two diseases remain to be elucidated. One difference, which might account for the increased airways responsiveness despite normal baseline calibre that is typical of asthma, is the relatively increased shedding of epithelial cells that is seen in asthma when compared to COPD. Increased epithelial shedding has been viewed as being characteristic of asthma, while squamous metaplasia is often encountered in smoking patients with COPD [5]. This points to different mechanisms involving the epithelial lining layer, which might be an important feature that differentiates the asthmatic from COPD phenotypes. It is generally believed that eosinophil activation plays a key role in epithelial damage by generating cationic proteins which are known to be toxic to the epithelium [34]. However, this study suggests that the extent of epithelial disruption cannot be accounted for solely by the toxic effects of ECP, since the asthmatics and subjects with COPD had similar levels of this basic protein. The correlation between airways hyperresponsiveness and ECP concentrations in sputum, which is restricted to asthmatics, suggests that the epithelium may be more susceptible to its effects and that this may account for increased airways responsiveness. There is increasing evidence that the epithelium has an altered phenotype in asthma that also involves increased susceptibility to insults incurred by oxidant stress [35]. It has been postulated that the presence of allergic inflammation per se is not 
sufficient to cause asthma, and that additional alterations in the epithelial cell response to injury are required for the full asthma syndrome to develop [36].

Based on sputum albumin levels measured in this study, it appears that the extent of plasma exudation found in COPD is not as high as in asthma, although a proportion of subjects with COPD had levels well above those found in control subjects and similar to those in asthma. This is in keeping with histological studies showing that mucosal vascular congestion is more evident in asthma than COPD $[37,38]$. In keeping with the current authors' previous report [15], it was found that the levels of the soluble form of sICAM-1 are raised in the sputum of asthmatics but the levels in COPD patients are intermediate when compared to asthma and the healthy state. Like those of albumin, sputum levels of sICAM-1 in COPD were highly variable, suggesting heterogeneity in the pathology in this group. These data are in line with studies on bronchial biopsies or brushings that have consistently shown increased airway cellular expression of ICAM-1 in asthma $[17,18]$, while the evidence for this in COPD has been unclear $[18,19]$.

In conclusion, when defined on the basis of reversibility testing to bronchodilators, asthma and chronic obstructive pulmonary disease share many inflammatory features. In a proportion of chronic obstructive pulmonary disease patients sputum eosinophilia is associated with mast-cell activation. Accumulating evidence suggests the relevance of these inflammatory features in determining the magnitude of response to corticosteroids. This study adds support to the view that asthma and chronic obstructive pulmonary disease need to be defined according to pathological as well as lung functional criteria.

\section{References}

1. American Thoracic Society. Standards for the diagnosis and care of patients with chronic obstructive pulmonary disease (COPD) and asthma. Am Rev Respir Dis 1987; 136: 225-243.

2. American Thoracic Society. Lung function testing: selection of reference values and interpretative strategies. Am Rev Respir Dis 1991; 144: 1202-1228.

3. Siafakas NM, Vermeire P, Pride NB, et al. Optimal assessment and management of chronic obstructive pulmonary disease (COPD). Eur Respir $J$ 1995; 8: 1398-1420.

4. British Thoracic Society. Guidelines for the management of COPD. Thorax 1997; 52: Suppl. 5, S1-S28.

5. Jeffery PK. Structural and inflammatory changes in COPD: a comparison with asthma. Thorax 1998; 53: 129-136.

6. Wenzel SE, Szefler SJ, Leung DYM, Sloan SI, Rex MD, Martin R. Bronchoscopic evaluation of severe asthma. Persistent inflammation associated with high dose glucocorticoids. Am J Respir Crit Care Med 1997; 156: 737-743.

7. Jatakanon A, Uasuf C, Maziak W, Lim S, Chung KF, Barnes P. Neutrophilic inflammation in severe persistent asthma. Am J Respir Crit Care Med 1999; 160: $1532-1539$.

8. Keatings V, Barnes P. Granulocyte activation markers in induced sputum: comparison between chronic obstructive pulmonary disease, asthma, and normal subjects. Am J Respir Crit Care Med 1997; 155: 449453.

9. Yamamoto C, Yoneda T, Yoshikawa M, et al. Airway inflammation in COPD assessed by sputum levels of interleukin-8. Chest 1997; 112: 505-510.

10. Balzano G, Stefanelli F, Iorio C, et al. Eosinophilic inflammation in stable chronic obstructive pulmonary disease. Relationship with neutrophils and airway function. Am J Respir Crit Care Med 1999; 160: 14861492.

11. Ronchi MC, Piragino C, Rosi E, et al. Do sputum eosinophils and ECP relate to the severity of asthma? Eur Respir J 1997; 10: 1809-1813.

12. Fujimoto K, Kubo K, Matsusawa Y, Sekigushi M. Eosinophil cationic protein levels in induced sputum correlate with the severity of bronchial asthma. Chest 1997; 112: 1241-1247.

13. Louis R, Lau L, Broon A, Roldam B, Radermecker M, Djukanovic R. Relationship between airway inflammation and asthma severity. Am J Respir Crit Care Med 2000; 161: 9-16.

14. Walls AF. Neutral proteases in asthma and rhinitis. In: Busse WW, Holgate ST, eds. Asthma and Rhinitis. 2nd Edn. Boston, Blackwell, 2000; pp. 968-998.

15. Louis R, Shute J, Biagi, et al. Cell infiltration, ICAM1 expression, and eosinophil chemotactic activity in asthmatic sputum. Am J Respir Crit Care Med 1997; 155: 460-472.

16. Yager D, Kamm RD, Drazen J. Airway wall liquid: sources and role as amplifier of bronchoconstriction. Chest 1995; 107: 105S-110S.

17. Bentley A, Durham S, Robinson D, et al. Expression of endothelial and leukocyte adhesion molecules intercellular adhesion molecule-1, E selectin, and vascular cell adhesion molecule-1 in the bronchial mucosa in steady-state and allergen-induced asthma. J Allergy Clin Immunol 1993; 92: 857-868.

18. Vignola MA, Campbell A, Chanez P, et al. HLA-DR and ICAM-1 expression on bronchial epithelial cells in asthma and chronic bronchitis. Am Rev Respir Dis 1993; 148: 689-694.

19. Di Stefano A, Maestrelli $\mathrm{P}$, Roggeri A, et al. Upregulation of adhesion molecules in the bronchial mucosa of subjects with chronic obstructive bronchitis. Am J Respir Crit Care Med 1994; 149: 803-810.

20. Weecke B. Rocket immunoelectrophoresis. Scand J Immunol 1974; 1: Suppl., 37-46.

21. Walls A, Bennett AR, McBride HM, Glennie MJ, Holgate ST, Church MK. Production and characterisation of monoclonal antibodies specific for human mast cell tryptase. Clin Exp Allergy 1990; 20: 581-589.

22. Wenzel S, Schwartz LB, Langmack E, et al. Evidence that severe asthma can be divided pathologically into two inflammatory subtypes with distinct physiologic and clinical characteristics. Am J Respir Crit Care Med 1999; 160: 1001-1008.

23. Paggiaro PL, Dahle R, Bakran I, Frith L, Hollingworth $\mathrm{K}$, Efthimiou J. Multicentre randomized placebo controlled trial of inhaled fluticasone proprionate in patients with chronic obstructive pulmonary disease. International COPD study group. Lancet 1998; 351: 773-780.

24. Pauwels RA, Löfdhal CD, Laitinen LA, et al. Longterm treatment with inhaled budesonide in persons with mild chronic obstructive pulmonary disease who 
continue smoking. New Engl J Med 1999; 340: 19481953.

25. Burge PS, Calverley PMA, Jones PW, Spencer S, Anderson JA, Malsen TK and on behalf of the ISOLDE study investigators. Randomised, double blind, placebo controlled study of fluticasone propionate in patients with moderate to severe chronic obstructive pulmonary disease: the ISOLDE trial. BMJ 2000; 320: 1297-1303.

26. Chanez P, Vignola AM, O'Shaugnessy T, Enander I, Li D, Jeffry PK, Bousquet J. Corticosteroid reversibility in COPD is related to features of asthma. Am J Respir Crit Care Med 1997; 155: 1529-1534.

27. Pizzichini E, Pizzichini MM, Gibson P, et al. Sputum eosinophilia predicts benefit from prednisolone in smokers with chronic obstructive bronchitis. $\mathrm{Am}$ J Respir Crit Care Med 1998; 159: 1511-1517.

28. Brightling CE, Monteirio W, Ward R, et al. Sputum eosinophilia and short-term response to prednisolone in chronic obstructive pulmonary disease: a randomized controlled trial. Lancet 2000; 356: 1480-1485.

29. Rutgers SR, Tiemens W, Tsanakis N, et al. Airway inflammation and hyperresponsiveness to adenosine 5 '-monophosphate in chronic obstructive pulmonary disease. Clin Exp Allergy 2000; 30: 657-662.

30. Hiemstra PS, van Wetering S, Stolk J. Neutrophil serine and proteinases and defensins in pulmonary disease: effects on pulmonary epithelium. Eur Respir $J$ 1998; 12: 1200-1208.

31. Papi A, Belletato CM, Zanin A, et al. Airway inflammation in asthma and chronic obstructive pulmonary disease (COPD) with similar degree of irreversible airflow limitation. Am J Respir Crit Care Med 2001; 163: A80.

32. Papi A, Romagnoli M, Baraldo S, et al. Partial reversibility of airflow limitation and increased exhaled NO and sputum eosinophilia in chronic obstructive pulmonary disease. Am J Respir Crit Care Med 2000; 162: 1773-1777.

33. Sur S, Glitz DG, Kita $\mathrm{H}$, et al. Localization of eosinophil-derived neurotoxin and eoinophil cationic protein in neutrophilic leukocytes. J Leukoc Biol 1998; 63: 715-722.

34. Gleich G. Eosinophil in asthma: current understanding. J Allergy Clin Immunol 1990; 85: 422-436.

35. Bucchieri $\mathrm{F}$, Lordan $\mathrm{J}$, Richter $\mathrm{A}$, et al. Increased sensitivity of asthmatic bronchial epithelial cells to oxydant-induced injury. Am J Respir Crit Care Med 2000; 161: A153.

36. Holgate ST, Davies DE, Lackie PM, Wilson SJ, Puddicombe SM, Lordan J. Epithelial-mesenchymal interactions in the pathogenesis of asthma. $J$ Allergy Clin Immunol 2000; 105: 193-204.

37. Kuwano K, Bosken C, Pare P, Bai T, Wiggs B, Hogg J. Small airways dimensions in asthma and in chronic obstructive pulmonary disease. Am Rev Respir Dis 1993; 148: 1220-1225.

38. Li X, Wilson JW. Increased vascularity of the bronchial mucosa in mild asthma. Am J Respir Crit Care Med 1997; 156: 229-233. 